\title{
Effects of protein content and the inclusion of protein sources with different amino acid release dynamics on the nitrogen utilization of weaned piglets
}

\author{
Nianzhi Hu' ${ }^{1}$, Zhiwen Shen ${ }^{1}$, Li Pan ${ }^{1}$, Guixin Qin ${ }^{1}$, Yuan Zhao ${ }^{1, *}$, and Nan Bao ${ }^{1, *}$
}

\author{
* Corresponding Authors: \\ Yuan Zhao \\ Tel: +86-18626923862 \\ E-mail: zhaoyuan4CL52@126.com \\ Nan Bao \\ Tel: +86-431-84532812, \\ E-mail: baonan203@163.com
}

'Key Laboratory of Animal Production, Product Quality and Security, Ministry of

Education, Jilin Provincial Key Laboratory of

Animal Nutrition and Feed Science, College

of Animal Science and Technology, Jilin

Agricultural University, Changchun 130118,

China

ORCID

Nianzhi Hu

https://orcid.org/0000-0001-9492-1916

Zhiwen Shen

https://orcid.org/0000-0003-1428-2283

Li Pan

https://orcid.org/0000-0002-0348-3955

Guixin Qin

https://orcid.org/0000-0001-6918-1709

Yuan Zhao

https://orcid.org/0000-0003-3523-9751

Nan Bao

https://orcid.org/0000-0002-6977-0797

Submitted Mar 25, 2021; Revised Apr 14, 2021; Accepted Jul 4, 2021

\begin{abstract}
Objective: We aimed to investigate the effect of the differing amino acid (AA) release dynamics of two protein sources on the growth performance, nitrogen deposition, plasma biochemical parameters, and muscle synthesis and degradation of piglets when included in their diets at normal and low concentrations.

Methods: Forty-eight piglets (Duroc $\times$ Landrace $\times$ Large White) with initial body weight of $7.45 \pm 0.58 \mathrm{~kg}$ were assigned to six groups and fed one of 6 diets. The 6 dietary treatments were arranged by $3 \times 2$ factorial with 3 protein sources and 2 dietary protein levels. They are NCAS (a normal protein content with casein), NBlend (a normal protein content with blend of casein and corn gluten meal), NCGM (a normal protein content with corn gluten meal), LCAS (a low protein content with casein), LBlend (a low protein content with blend of casein and corn gluten meal), LCGM (a low protein content with corn gluten meal). The release dynamics of AA in these diets were determined by in vitro digestion. The digestibility, utilization and biological value of nitrogen in piglets were determined by micro Kjeldahl method. Plasma insulin was measured by enzyme-linked immunosorbent assay kits. The protein expression of mediators of muscle synthesis and degradation was determined by western blotting.

Results: Although the consumption of a low-protein diet supplemented with crystalline AA was associated with greater nitrogen digestion and utilization $(\mathrm{p}<0.05)$, the final body weight, growth performance, nitrogen deposition, and phosphorylation of ribosomal protein S6 kinase 1 and eIF4E binding protein 1 in the muscle of pigs in the low-protein diet-fed groups were lower than those of the normal-protein diet-fed groups $(\mathrm{p}<0.05)$ because of the absence of non-essential AA. Because of the more balanced release of AA, the casein (CAS) and Blend-fed groups showed superior growth performance, final body weight and nitrogen deposition, and lower expression of muscle ring finger 1 and muscle atrophy F-box than the CGM-fed groups $(\mathrm{p}<0.05)$.

Conclusion: We conclude that the balanced release of AA from CAS containing diets and mixed diets could reduce muscle degradation, favor nitrogen retention, \% intake and improve growth performance in pigs consuming either a normal- or low-protein diet.
\end{abstract}

Keywords: Amino Acid Release Dynamics; Dietary Protein Content; Dietary Protein Source; Piglet

\section{INTRODUCTION}

The shortage of high-quality nitrogen resources and the environmental pollution caused by fecal and urinary nitrogen loss have always been challenges in pig production [1]. In particular, although diets containing high levels of crude protein (CP) promote the normal development of weaned piglets, they are associated with the above problems and with the risk of intestinal diseases in piglets [2]. A series of previous studies have shown that 
piglets fed a diet with a low CP content (no more than 3\% unit less than standard) that is supplemented with free amino acids (FAA) lose less nitrogen and are cheaper to feed, and they demonstrate appropriate growth performance and have a lower risk of developing gastrointestinal tract (GIT) diseases [3-5].

The final degradation products of intact protein in the GIT are FAA and peptides [6], which enter intestinal capillaries and are transported to the liver for protein synthesis. Thus, the utilization of protein by animals is related with utilization of amino acids (AA). In the current feed evaluation system [7], the nutritional needs of pigs are estimated according to the composition and ileal terminal digestibility of AA. However, the digestion and absorption of feed materials in the GIT of animals is a dynamic process that is not reflected in these parameters [7].

Previous study has shown that the consumption of whey protein, which is rapidly digested, leads to earlier postprandial hyperaminoacidemia and peak protein synthesis because most of the AA are released quite proximally in the GIT, which means that FAA enter the portal circulation rapidly [8]. However, this will also result in excessive degradation of high-quality AA (i.e., essential amino acids, EAA) in the GIT, and it comes to be a waste of nitrogen. Conversely, the consumption of casein (CAS), which is digested more slowly, is associated with a shallower protein synthesis peak and less protein degradation in the GIT, such that the total protein deposition is higher than that achieved following the consumption of whey protein [9]. Study suggested that a mixture of proteins (fast and slow AA-releasing) provides the advantages of both types because the rapid appearance and maintenance of a high concentration of AA prolong hyperaminoacidemia and increase protein retention [10].

The incubation of diets with pepsin and trypsin has been shown to be an effective means of simulating in vivo digestion in the porcine GIT [11]. In addition, the dynamics of the digestion of diets can be reflected to some extent by measuring the FAA concentrations in the in vitro residue at various time points [12]. On the basis of such studies, we have shown that CAS releases its AA faster than soybean meal (SBM) [6], and SBM releases its AA faster than corn gluten meal (CGM) [13]. In the present study, CAS or CGM were included in six diets at two kinds of CP levels (normal or low), and we aimed to i) determine their AA release dynamics in vitro, and ii) identify the relationship between the dynamics of AA release and nitrogen deposition in piglets consuming the diets by measuring their growth performance, blood biochemical indices, nitrogen balance, and protein expression of mediators of muscle synthesis and degradation. The overall objective of the study was to identify the optimal ways of using nitrogen resources, reducing production costs and protecting the environment in pig production.

\section{MATERIALS AND METHODS}

\section{Animal care}

This study was approved by the Animal Care and Use Committee of Jilin Agricultural University (process number: KT2019012). The experimental procedures, including animal care, were managed in strict accordance with the "Regulations on the Management of Experimental Animals (November 17, 2016)" issued by Jilin Provincial People's Government.

\section{Animals, housing, experimental design and diet}

Forty-eight hybrid piglets (Duroc $\times$ Landrace $\times$ Large White) with an initial body weight of $7.45 \pm 0.58 \mathrm{~kg}$ were allocated to 6 treatments of 4 replicates each with 2 pigs per replicate, according to their body mass and sex in a completely randomized design. Treatments were designed by a $2 \times 3$ factorial arrangement of treatments, and the main factors were 2 different CP levels and 3 different protein sources of the diet.

The experimental diets contained either a normal protein concentration (CP 17.5\% standardized ileal digestible, SID) or a low protein concentration (CP 14.8\%, SID). Three diets were prepared in each category according to the release rate of AA: a CAS-based diet, a CGM-based diet, and a diet containing a mixture of the two (CAS+CGM; Blend). The diets were formulated (Table 1) to meet the estimated nutrient requirements for piglets [7]. The overall concentrations of various AA in each diet were balanced by adding crystalline amino acids (CAA) and the other components of the low-protein diets were present at similar concentrations to those in the normal-protein diets.

The study was performed in the livestock housing of Jilin Agricultural University, which is maintained at a temperature of $25^{\circ} \mathrm{C}$. Piglets were fed three times a day, at 0700,1200 , and 1800 , such that a small amount of feed remained each time. They had free access to water from teat dispensers. The piglets were permitted to adapt to their environment for 5 days, then they were fed the diets for 28 days, and their daily feed intake and body weight were measured at the start and end of the trial, on days 6 and 33. These values were used to calculate the average daily feed intake (ADFI), average daily gain (ADG), and gain-to-feed ratio (G:F).

\section{Determination of the amino acid release rates for each diet}

In vitro digestion experiment: Following the methods of Bai et al [12] and Abdallah et al [13] which was modified from the method developed by Boisen and Ferna'ndez [11], $1 \mathrm{~g}$ of each feed sample (measured to $0.001 \mathrm{~g}$ ) was placed in 100 $\mathrm{mL}$ conical flasks, with three replicates per diet. Ten milliliters of freshly prepared $1 \mathrm{mg} / \mathrm{mL}$ pepsin $(\mathrm{pH} 2)$ and $0.5 \mathrm{~mL}$ chloramphenicol solution ( $0.5 \mathrm{~g}$ chloramphenicol in 100 
Table 1. Ingredients and calculated nutrient composition of experimental diet (as-fed basis)

\begin{tabular}{|c|c|c|c|c|c|c|}
\hline \multirow{2}{*}{ Items } & \multicolumn{6}{|c|}{ Diet } \\
\hline & NCAS & NBlend & NCGM & LCAS & LBlend & LCGM \\
\hline \multicolumn{7}{|l|}{ Ingredient (\%) } \\
\hline Corn & 64.02 & 58.03 & 52.05 & 68.47 & 63.18 & 57.90 \\
\hline Wheat bran & 2.00 & 2.00 & 2.00 & 2.00 & 2.00 & 2.00 \\
\hline Soybean meal & 17.40 & 18.38 & 19.35 & 12.28 & 14.28 & 16.27 \\
\hline Casein & 7.07 & 3.54 & - & 6.00 & 3.00 & - \\
\hline Corn gluten meal & - & 7.34 & 14.68 & - & 5.27 & 10.54 \\
\hline Sucrose & 3.00 & 3.00 & 3.00 & 3.00 & 3.00 & 3.00 \\
\hline Soybean oil & 1.10 & 2.16 & 3.21 & 1.17 & 2.13 & 3.10 \\
\hline L-Arg, 99.7\% & 0.06 & 0.03 & - & 0.20 & 0.18 & 0.16 \\
\hline L-Ile, $100.0 \%$ & 0.09 & 0.05 & - & 0.22 & 0.19 & 0.16 \\
\hline L-Leu, 99.2\% & 0.79 & 0.40 & - & 1.00 & 0.72 & 0.44 \\
\hline L-Cys, 99.3\% & - & 0.03 & 0.06 & 0.09 & 0.11 & 0.13 \\
\hline L-Tyr, 99.9\% & - & 0.21 & 0.41 & 0.24 & 0.30 & 0.36 \\
\hline L-His, 99.5\% & - & 0.02 & 0.04 & 0.07 & 0.10 & 0.12 \\
\hline L-Lys.HCL, 78.8\% & 0.28 & 0.45 & 0.61 & 0.48 & 0.60 & 0.73 \\
\hline DL-Met, 99.5\% & 0.01 & 0.03 & 0.05 & 0.07 & 0.09 & 0.11 \\
\hline L-Phe, $100.0 \%$ & - & 0.23 & 0.45 & 0.26 & 0.33 & 0.39 \\
\hline L-Thr, 99.5\% & 0.12 & 0.12 & 0.11 & 0.22 & 0.22 & 0.22 \\
\hline L-Trp, 99.5\% & 0.01 & 0.02 & 0.04 & 0.04 & 0.05 & 0.06 \\
\hline L-Val, 99.3\% & 0.05 & 0.04 & 0.03 & 0.16 & 0.16 & 0.17 \\
\hline Limestone & 1.00 & 1.01 & 1.02 & 0.88 & 0.99 & 1.09 \\
\hline Dicalcium phosphate & 1.15 & 1.10 & 1.05 & 1.18 & 1.18 & 1.19 \\
\hline Salt & 0.85 & 0.84 & 0.84 & 0.85 & 0.85 & 0.84 \\
\hline Premix ${ }^{1)}$ & 1.00 & 1.00 & 1.00 & 1.00 & 1.00 & 1.00 \\
\hline \multicolumn{7}{|l|}{ Nutrient levels (\%) } \\
\hline Net energy (MJ/kg) & 10.26 & 10.26 & 10.25 & 10.25 & 10.26 & 10.26 \\
\hline Crude protein & 19.79 & 21.23 & 22.95 & 17.08 & 17.84 & 18.36 \\
\hline Crude protein (SID) & 17.54 & 17.54 & 17.53 & 14.89 & 14.89 & 14.88 \\
\hline $\operatorname{Arg}(S I D)$ & 1.06 & 1.06 & 1.06 & 1.07 & 1.07 & 1.07 \\
\hline His (SID) & 0.49 & 0.49 & 0.49 & 0.48 & 0.48 & 0.48 \\
\hline Ile (SID) & 0.85 & 0.85 & 0.85 & 0.85 & 0.85 & 0.85 \\
\hline Leu (SID) & 2.43 & 2.43 & 2.42 & 2.43 & 2.43 & 2.43 \\
\hline Lys (SID) & 1.35 & 1.35 & 1.35 & 1.35 & 1.35 & 1.35 \\
\hline Met+Cys (SID) & 1.24 & 1.24 & 1.24 & 1.24 & 1.24 & 1.24 \\
\hline Phe+Tyr (SID) & 3.26 & 3.26 & 3.25 & 3.25 & 3.25 & 3.25 \\
\hline $\operatorname{Thr}(\mathrm{SID})$ & 0.79 & 0.79 & 0.79 & 0.79 & 0.79 & 0.79 \\
\hline $\operatorname{Trp}(S I D)$ & 0.22 & 0.22 & 0.22 & 0.22 & 0.22 & 0.22 \\
\hline Val (SID) & 0.94 & 0.93 & 0.91 & 0.86 & 0.86 & 0.86 \\
\hline Crude fiber & 1.73 & 1.74 & 1.75 & 1.63 & 1.67 & 1.70 \\
\hline $\mathrm{Ca}$ & 0.80 & 0.80 & 0.80 & 0.80 & 0.80 & 0.80 \\
\hline Available P & 0.40 & 0.40 & 0.40 & 0.40 & 0.40 & 0.40 \\
\hline
\end{tabular}

NCAS, diet with normal protein content, based on casein; NBlend, diet with normal protein content, based on casein and corn gluten meal; NCGM, diet with normal protein content, based on corn gluten meal; LCAS, diet with low protein content, based on casein; LBlend, diet with a low protein content, based on casein and corn gluten meal; LCGM, diet with low protein content, based on corn gluten meal; SID, standardized ileal digestible.

1) Supplied the following per kilogram of diet: vitamin $A, 5,000 \mathrm{IU}$; vitamin $D_{3}, 500 \mathrm{IU}$; vitamin $\mathrm{E}, 20 \mathrm{mg}$; vitamin $\mathrm{K}, 2$ mg; vitamin $B_{6}, 4$ mg; vitamin $B_{12}, 4$ mg; vitamin $\mathrm{B}_{1}, 1.5 \mathrm{mg}$; biotin, $0.10 \mathrm{mg}$; folic acid, $0.50 \mathrm{mg}$; nicotinic acid, $25 \mathrm{mg}$; pantothenic acid, $2 \mathrm{mg}$; riboflavin, 4 mg; oxytetracycline, $50 \mathrm{mg}$; antioxidant, 100 mg; Fe, 200 mg as $\mathrm{FeSO}_{4} ; \mathrm{Cu}, 20 \mathrm{mg}$ as $\mathrm{CuSO}_{4} ; \mathrm{Mn}, 0.10 \mathrm{mg}$ as $\mathrm{MnSO}_{4} ; \mathrm{Co}, 0.10 \mathrm{mg}$ as $\mathrm{CoCO}_{3} ; \mathrm{Zn}, 250 \mathrm{mg}$ as ZnO; I, $0.5 \mathrm{mg}$ as $\mathrm{KIO}_{3} ; \mathrm{Se}_{1} 1 \mathrm{mg}$ as Na $2 \mathrm{SeO}_{3}$.

$\mathrm{mL}$ ethanol) were added to the conical flasks, which were sealed and incubated in a water bath oscillator at $39^{\circ} \mathrm{C}$ for $4 \mathrm{~h}$. At the end of the incubation, the conical flasks were removed, $10 \mathrm{~mL}$ phosphate buffer $(\mathrm{pH} 6.8)$ was added, and the $\mathrm{pH}$ was adjusted to 6.8 using $1 \mathrm{M} \mathrm{NaOH}$. One milliliter of $50 \mathrm{mg} / \mathrm{mL}$ trypsin solution was then added, the contents were mixed, and the flasks were re-covered with sealing membrane and incubated at $39^{\circ} \mathrm{C}$ for a further $0,4,8,12,16$, 20,24 , and $28 \mathrm{~h}$. The solutions were centrifuged at $2,000 \times \mathrm{g}$ and $4^{\circ} \mathrm{C}$ for $15 \mathrm{~min}, 800 \mu \mathrm{L}$ of each supernatant were passed through $0.22 \mu \mathrm{m}$ filters, $200 \mu \mathrm{L} 10 \%$ sulfosalicylic acid was added, and the mixtures were incubated at $4^{\circ} \mathrm{C}$ for $1 \mathrm{~h}$ and 
then centrifuged at $8,000 \times \mathrm{g}$ for $10 \mathrm{~min}$. The supernatants were then filtered through $0.22 \mu \mathrm{m}$ filters and stored at $-80^{\circ} \mathrm{C}$ until analysis.

Chromatographic conditions: As previously described by Abdallah et al [13], an Acquity ultra-high performance liquid chromatography (UPLC) tunable ultraviolet system (Waters, Milford, MA, USA) was used. The chromatographic column was an AccQ.Tag Ultra column $(2.1 \times 100 \mathrm{~mm}, \mathrm{P} / \mathrm{N}$ : 186003837), mobile phase A was $10 \%$ AccQ.tagUltra eluent A, mobile phase B was AccQ.tagUltra eluent B, the flow rate was $0.7 \mathrm{~mL} / \mathrm{min}$, the injection volume was $1 \mu \mathrm{L}$, the column temperature was $55^{\circ} \mathrm{C}$, the sample temperature was $15^{\circ} \mathrm{C}$, the detection wavelength was $260 \mathrm{~nm}$, the collection speed was 20 points $/ \mathrm{s}$, the time constant was $0.1 \mathrm{~s}$, and the running time was $10 \mathrm{~min}$.

Pre-column derivation: One milliliter of AccQ fluor diluent from the $2 \mathrm{~B}$ bottle was injected into the $2 \mathrm{~A}$ (AccQ Fluor reagent powder) bottle, vortexed, and incubated at $55^{\circ} \mathrm{C}$ for 10 min. Seventy milliliters of AccQ.Fluor.Buffer 1 and $10 \mathrm{~mL}$ of sample were added to derivative tubes (P/NWT007571), followed by $20 \mathrm{~mL}$ of AccQ Fluor derivative (2A), and the tubes were mixed for $15 \mathrm{~s}$ and placed in a $55^{\circ} \mathrm{C}$ oven for $10 \mathrm{~min}$ after standing for $1 \mathrm{~min}$ at room temperature. The derivatives were then transferred to UPLC full recovery sample bottles.

Creation of free amino acid curves: Graphs of AA release during trypsin digestion were plotted using Graphpad Prism version 8.0 (GraphPad Software, San Diego, CA, USA). We considered that the AA would be almost completely released by $28 \mathrm{~h}$. Therefore, the percentage FAA release was calculated by dividing the FAA concentrations at $0,4,8,12,16,20,24$, and $28 \mathrm{~h}$ by those at $28 \mathrm{~h}$. The absolute differences between the individual FAA release percentage curves and the total free amino acid (TFAA) release curves were then calculated.

\section{Nitrogen balance}

After assessing the growth of the piglets, nitrogen balance was assessed from day 34 of the study. Four piglets with body weight closest to the mean values were selected from each diet group and placed into metabolic pens with slatted floor and urine collector, where they were fed two meals daily, at $0900 \mathrm{~h}$ and $1600 \mathrm{~h}$. The nitrogen balance experimental diets were the same as the growth performance experimental diets. After 3 days of adaptation, the feces and urine of each pig were collected for 4 consecutive days. All feces were collected at $0900 \mathrm{~h}$ a day after feeding, weighed and frozen at $-20^{\circ} \mathrm{C}$. After the trial, the feces were thawed and homogenized, and $10 \%$ of the final weight of the sample was taken. The fecal sample was dried in an oven at $65^{\circ} \mathrm{C}$ and then crushed in high-speed multifunction crusher (FW100, Tester, Tianjin, China). Comminuted fecal sample was stored at $-20^{\circ} \mathrm{C}$ for measurement. After feeding at $0900 \mathrm{~h}$ and $1600 \mathrm{~h}$ twice daily, the whole urine in the urine collector was removed and weighed, and subsequently filtered with gauze, taking $10 \%$ of the total weight into a clean container. Twenty $\mathrm{mL}$ of $2 \mathrm{M}$ sulfuric acid was added to the urine collector for nitrogen fixation before each collection. After the trial, the urine samples were thawed and mixed and then frozen at $-20^{\circ} \mathrm{C}$ for subsequent analysis. The nitrogen content of the samples was measured using a fully automatic Kjeldahl nitrogen analyzer (Foss, Hillerød, Denmark) according to Kjeldahl method [14] and the nitrogen digestibility, nitrogen retention, \% intake and nitrogen biological value were calculated.

$$
\begin{aligned}
& \text { Nitrogen digestibility }(\%) \\
& =(\text { nitrogen intake }- \text { fecal nitrogen }) \\
& \quad / \text { nitrogen intake } \times 100 \%
\end{aligned}
$$
Nitrogen retention, \% intake (\%)
$=($ nitrogen intake - fecal nitrogen - urine nitrogen $)$
/ nitrogen intake $\times 100 \%$

$$
\begin{aligned}
& \text { Nitrogen biological value }(\%) \\
& =(\text { nitrogen intake }- \text { fecal nitrogen }- \text { urine nitrogen }) / \\
& \quad(\text { nitrogen intake }- \text { fecal nitrogen }) \times 100 \%
\end{aligned}
$$

\section{Serum and tissue sample collection}

On day 33 of the study, $10 \mathrm{~mL}$ blood was collected from a jugular vein of each piglet into heparinized tubes, and the separated plasma was stored at $-80^{\circ} \mathrm{C}$ for subsequent measurements. On day 34, 2 hours after feeding at $0700 \mathrm{~h}$, the piglets were anesthetized, blood samples were obtained, and samples of the longissimus dorsi muscle were collected and immediately transferred to $-80^{\circ} \mathrm{C}$ for subsequent analysis.

\section{Determination of plasma biochemical indices}

Plasma urea nitrogen (PUN) was measured using an automatic biochemical analyzer (Biobase, Shandong, China). Plasma insulin concentration was determined using enzymelinked immunosorbent assay kits (Mbbiology, Jiangsu, China), according to the manufacturer's instructions.

\section{Measurement of the expression of mediators of muscle synthesis and degradation}

The protein expression of mammalian target of rapamycin (mTOR) pathway and the ubiquitin-proteasome pathway (UPP) intermediates in longissimus dorsi muscles was determined by western blotting. Briefly, the muscle samples were ground in mortars under liquid nitrogen and lysates were prepared in radio immunoprecipitation assay lysis buffer (strong) (Cwbio, Beijing, China) supplemented with phosphatase and protease inhibitors (Cwbio, China). The protein concentrations of the lysates were quantified using bicinchoninic acid assay protein kits (Cwbio, China). The protein concentrations of the lysates were equalized, and the lysates 
were mixed with loading buffer and heated in boiling water for $10 \mathrm{~min}$. Polyacrylamide gel electrophoresis was performed, and then the proteins were transferred to polyvinylidene fluoride membranes (Millipore, Burlington, MA, USA). The membranes were then blocked using $5 \%$ fetal bovine serum at room temperature for $1 \mathrm{~h}$ and incubated overnight at $4^{\circ} \mathrm{C}$ with antibodies targeting phosphorylated ribosomal protein S6 kinase (p-S6K1), muscle atrophy F-box (MAFbx), muscle ring finger 1 (MuRF1) (Abclonal, Wuhan, China), or phosphorylated elF 4E binding protein-1 (p-4E-BP1) (Bios, Beijing, China). The next day, the membranes were incubated with secondary antibody at room temperature for $1 \mathrm{~h}$. Polyvinylidene fluoride membranes were imaged using the Kodak gel imaging system (Kodak, Rochester, New York, USA) after reacting the membranes for approximately $1 \mathrm{~min}$ in the dark with electrochemiluminescence developing solution (Cwbio, China). The intensities of the specific bands were analyzed using Image J (NIH, Bethesda, MD, USA) and the relative expression of each protein was calculated.

\section{Statistical analysis}

The data were analyzed using SPSS version 20.0 (IBM, Inc., Armonk, NY, USA). Protein content, protein source and their interaction effects were analyzed with general linear model univariate for two-way analysis of variance (ANOVA). When there was interaction between protein content and

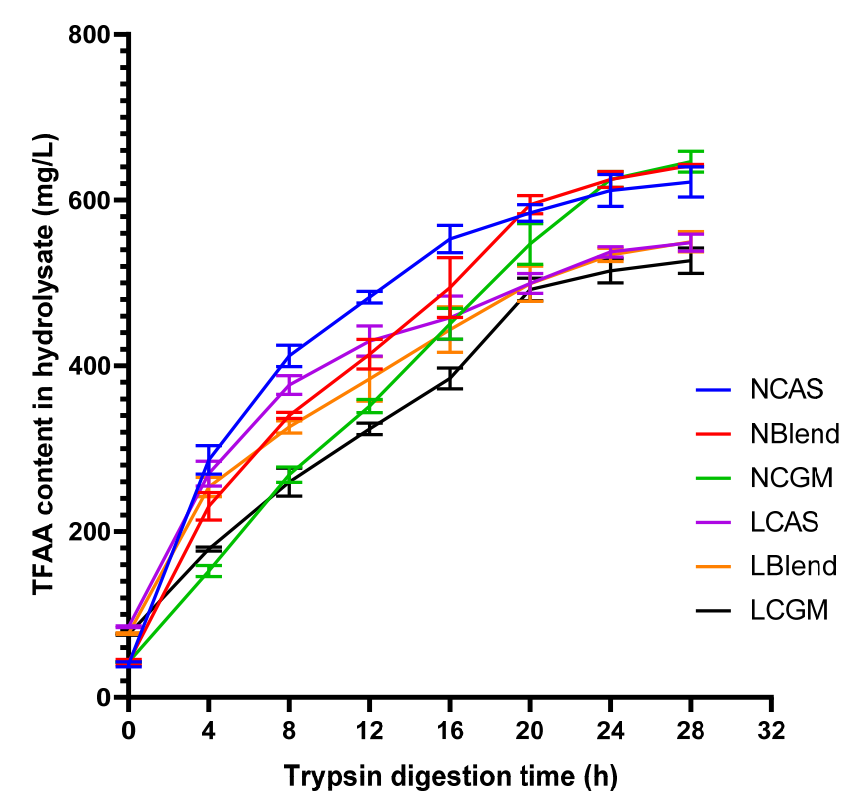

Figure 1. Total free amino acid release from each diet over time. NCAS, diet with normal protein content, based on casein; NBlend, diet with normal protein content, based on casein and corn gluten meal; NCGM, diet with normal protein content, based on corn gluten meal; LCAS, diet with low protein content, based on casein; LBlend, diet with a low protein content, based on casein and corn gluten meal; LCGM, diet with low protein content, based on corn gluten meal; TFAA, total free amino acid concentration. protein source, means of the six treatments were analyzed by multiple comparisons using the LSD method of one-way ANOVA. The data are expressed as means and standard errors of the mean (SEM). Each pen was the experimental unit. Statistical significance was accepted at $\mathrm{p}<0.05$.

\section{RESULTS}

\section{Release dynamics of amino acids}

As shown in Figure 1, TFAA content in hydrolysate of normal protein diet was higher than that of low protein diet. As shown in Figure 2, in the CAS-containing diet and the mixed diet, the peak of FAA release content per $4 \mathrm{~h}$ was in the early stage of trypsin digestion, while in the CGM group, the peak of FAA release content per $4 \mathrm{~h}$ was in the late stage of trypsin digestion. As shown in Figure 3, there were different AA release percentage curves among different treatments. To quantify the disparities between AA release, we calculated the areas between the individual FAA and TFAA curves. As shown in Table 2 and Figure 4, the CAS-containing diet and the mixed diet had lower area between the curves compared with the CGM-containing diet $(\mathrm{p}<0.05)$. Protein content had no significant effect on area between the curves.

\section{Growth performance}

As shown in Table 3, the CAS containing diet and the mixed diet had higher final body weight, ADG and G:F ratio compared with the CGM-containing diet $(\mathrm{p}<0.05)$. Diet with normal protein content had higher final body weight, ADG and G:F ratio than diet with low protein content $(\mathrm{p}<0.05)$.

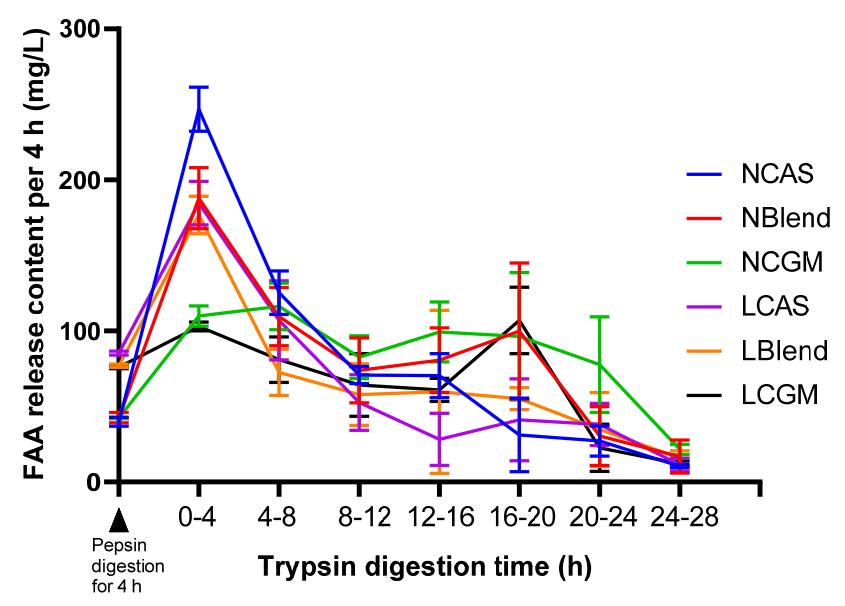

Figure 2. Free amino acid release from each diet during $4 \mathrm{~h}$ time intervals. At the zero time point, the diet had been digested using pepsin for $4 \mathrm{~h}$. NCAS, diet with normal protein content, based on casein; NBlend, diet with normal protein content, based on casein and corn gluten meal; NCGM, diet with normal protein content, based on corn gluten meal; LCAS, diet with low protein content, based on casein; LBlend, diet with a low protein content, based on casein and corn gluten meal; LCGM, diet with low protein content, based on corn gluten meal. 


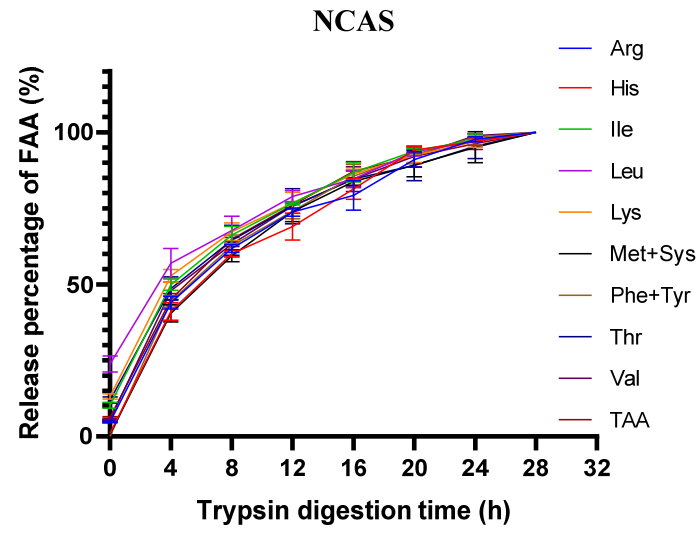

NBlend

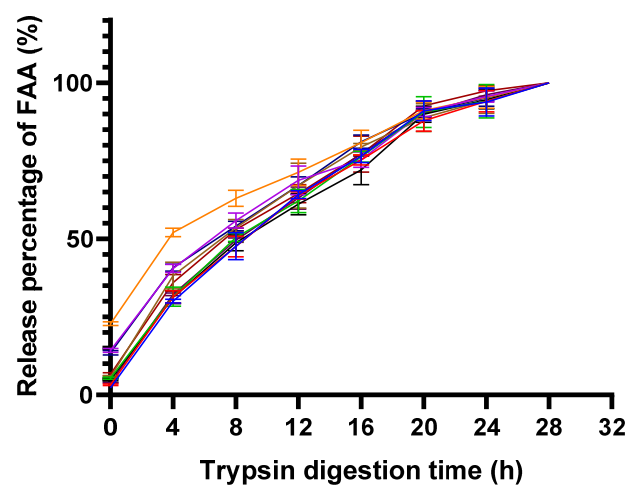

NCGM

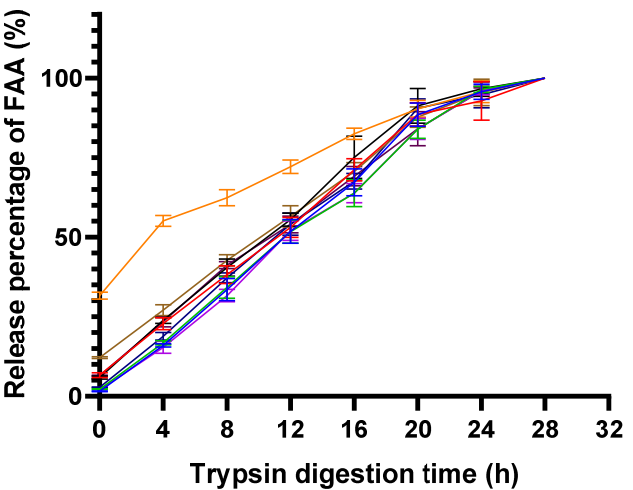

LCAS

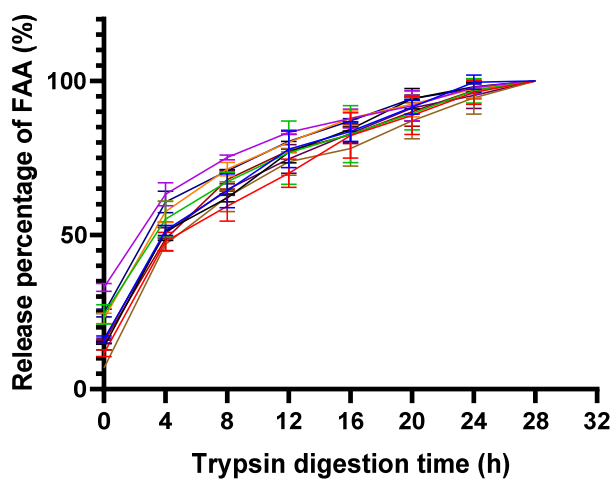

LBlend

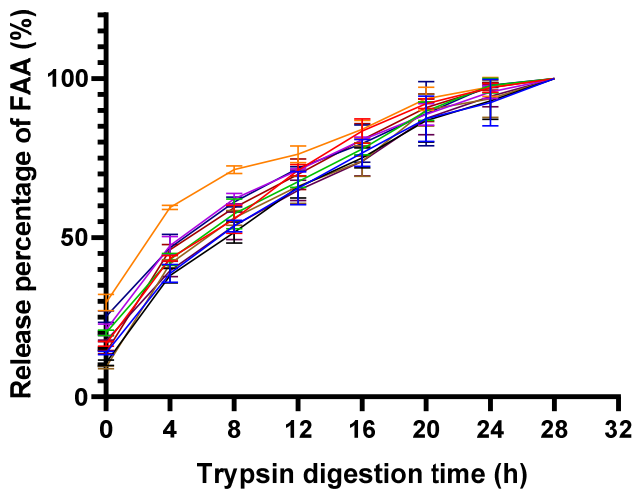

LCGM

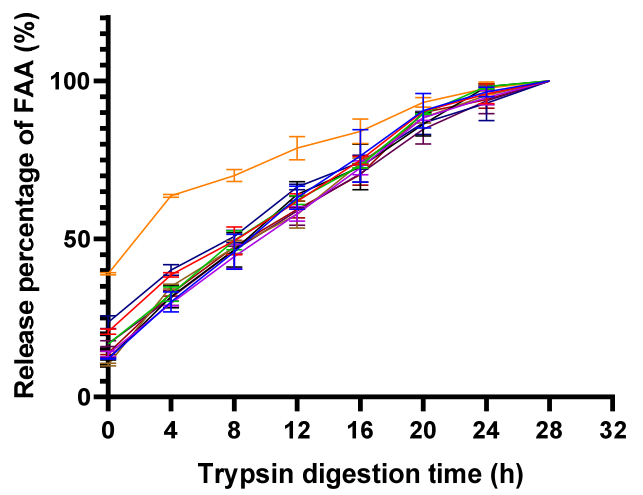

Figure 3. Percentage release of AA from diets over time. NCAS, diet with normal protein content, based on casein; NBlend, diet with normal protein content, based on casein and corn gluten meal; NCGM, diet with normal protein content, based on corn gluten meal; LCAS, diet with low protein content, based on casein; LBlend, diet with a low protein content, based on casein and corn gluten meal; LCGM, diet with low protein content, based on corn gluten meal; TAA, total free amino acids.

Table 2. Absolute differences in the areas under the curves for the percentage release of individual free amino acids and the amino acids as a whole $(n=3)$

\begin{tabular}{|c|c|c|c|c|c|c|c|c|c|c|c|c|c|c|c|}
\hline \multirow{2}{*}{ Parameter } & \multicolumn{3}{|c|}{ Protein source } & \multicolumn{2}{|c|}{ Protein content } & \multicolumn{6}{|c|}{ Diet } & \multirow{2}{*}{ SEM } & \multicolumn{3}{|c|}{ p-value } \\
\hline & CAS & Blend & CGM & Normal & Low & NCAS & NBlend & NCGM & LCAS & LBlend & LCGM & & Source & Content & $S \times C$ \\
\hline Area & $638^{b}$ & $770^{b}$ & $996^{a}$ & 817 & 786 & 613 & 717 & 1121 & 664 & 823 & 872 & 33.41 & $<0.01$ & 0.657 & 0.107 \\
\hline
\end{tabular}

NCAS, diet with normal protein content, based on casein; NBlend, diet with normal protein content, based on casein and corn gluten meal; NCGM, diet with normal protein content, based on corn gluten meal; LCAS, diet with low protein content, based on casein; LBlend, diet with a low protein content, based on casein and corn gluten meal; LCGM, diet with low protein content, based on corn gluten meal; SEM, standard errors of the mean.

$a, b$ Within the same row, different superscript letters represent significant differences with respect to protein content, source, or both ( $p<0.05)$. 


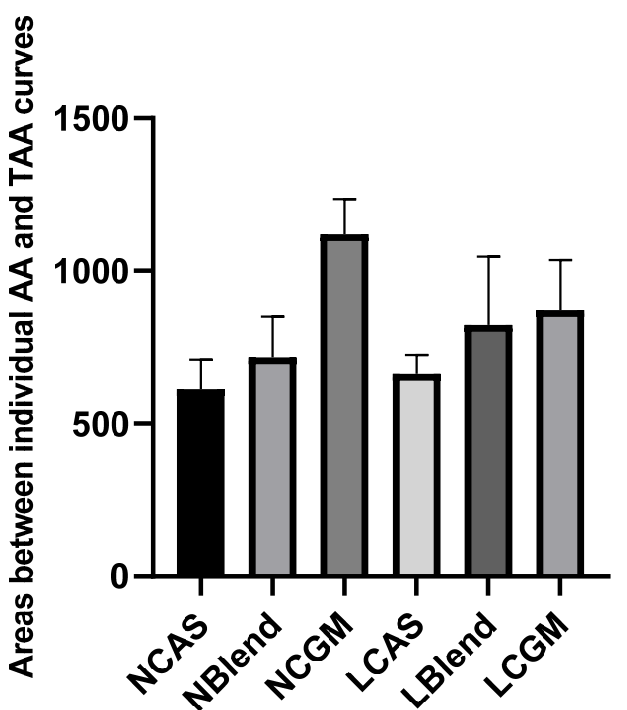

Figure 4. Absolute differences in the areas under the curves for the percentage release of individual free amino acids and the amino acids as a whole. NCAS, diet with normal protein content, based on casein; NBlend, diet with normal protein content, based on casein and corn gluten meal; NCGM, diet with normal protein content, based on corn gluten meal; LCAS, diet with low protein content, based on casein; LBlend, diet with a low protein content, based on casein and corn gluten meal; LCGM, diet with low protein content, based on corn gluten meal.

\section{Nitrogen balance}

As shown in Table 4, the CAS-containing diet and the mixed diet had higher nitrogen retention and nitrogen biological value compared with the CGM-containing diet $(\mathrm{p}<0.05)$. Diet with normal protein content had higher nitrogen loss and nitrogen retention and lower nitrogen digestibility, nitrogen retention, \% intake, nitrogen biological value than diet with low protein content $(\mathrm{p}<0.05)$. There were interactions between protein source and protein content with respect to urine nitrogen content. The urine nitrogen content of the NCGM group was higher than that of the other groups ( $\mathrm{p}<$ 0.01 ), but there was no difference between the NBlend and NCGM groups. The urine nitrogen content of the normalprotein groups was higher than that of the low-protein groups $(p<0.01)$, but there were no differences among the three lowprotein groups.

\section{Serum biochemical indices}

As shown in Table 5, there were no differences in insulin concentration between the groups. Plasma urea nitrogen was higher in normal-protein diet than in low-protein diet and lower in CAS-containing diet and mixed diet than in CGM-containing diet $(\mathrm{p}<0.05)$.

Table 3. Growth performance of piglets fed diets with differing protein content and source $(n=4)$

\begin{tabular}{|c|c|c|c|c|c|c|c|c|c|c|c|c|c|c|c|}
\hline \multirow{2}{*}{ Parameter } & \multicolumn{3}{|c|}{ Protein source } & \multicolumn{2}{|c|}{ Protein content } & \multicolumn{6}{|c|}{ Diet } & \multirow{2}{*}{ SEM } & \multicolumn{3}{|c|}{$\mathrm{p}$-value } \\
\hline & CAS & Blend & CGM & Normal & Low & NCAS & NBlend & NCGM & LCAS & LBlend & LCGM & & Source & Content & $S \times C$ \\
\hline Initial & 7.49 & 7.46 & 7.42 & 7.45 & 7.47 & 7.48 & 7.49 & 7.38 & 7.50 & 7.43 & 7.47 & 0.087 & 0.947 & 0.932 & 0.942 \\
\hline Final BW (kg) & $16.78^{a}$ & $16.68^{a}$ & $15.96^{b}$ & 17.07 & 15.87 & 17.43 & 17.25 & 16.53 & 16.12 & 16.12 & 15.38 & 0.108 & 0.012 & $<0.01$ & 0.941 \\
\hline $\operatorname{ADFI}(\mathrm{g} / \mathrm{d})$ & 503 & 500 & 494 & 501 & 497 & 503 & 501 & 498 & 502 & 499 & 490 & 2.179 & 0.297 & 0.406 & 0.743 \\
\hline ADG $(g / d)$ & $344^{a}$ & $342^{a}$ & $316^{b}$ & 356 & 311 & 368 & 362 & 339 & 319 & 322 & 293 & 3.139 & $<0.01$ & $<0.01$ & 0.839 \\
\hline G:F ratio & $0.684^{\mathrm{a}}$ & $0.683^{a}$ & $0.639^{b}$ & 0.711 & 0.626 & 0.732 & 0.721 & 0.680 & 0.636 & 0.645 & 0.598 & 0.005 & $<0.01$ & $<0.01$ & 0.692 \\
\hline
\end{tabular}

NCAS, diet with normal protein content, based on casein; NBlend, diet with normal protein content, based on casein and corn gluten meal; NCGM, diet with normal protein content, based on corn gluten meal; LCAS, diet with low protein content, based on casein; LBlend, diet with a low protein content, based on casein and corn gluten meal; LCGM, diet with low protein content, based on corn gluten meal; SEM, standard errors of the mean; BW, body weight; ADFI, average daily feed intake; ADG: average daily gain; G:F ratio: gain-to-feed ratio.

${ }_{a, b}$ Within the same row, different superscript letters represent significant differences with respect to protein content, source, or both $(p<0.05)$.

Table 4. Nitrogen balance of piglets fed diets with differing protein content and source $(n=4)$

\begin{tabular}{|c|c|c|c|c|c|c|c|c|c|c|c|c|c|c|c|}
\hline \multirow{2}{*}{ Parameter } & \multicolumn{3}{|c|}{ Protein source } & \multicolumn{2}{|c|}{ Protein content } & \multicolumn{6}{|c|}{ Diet } & \multirow{2}{*}{ SEM } & \multicolumn{3}{|c|}{ p-value } \\
\hline & CAS & Blend & CGM & Normal & Low & NCAS & NBlend & NCGM & LCAS & LBlend & LCGM & & Source & Content & $S \times C$ \\
\hline Nitrogen intake (g/d) & $25.76^{c}$ & $26.53^{b}$ & $27.38^{\mathrm{a}}$ & 29.23 & 23.88 & 28.25 & 29.11 & 30.34 & 23.27 & 23.95 & 24.42 & 0.116 & $<0.01$ & $<0.01$ & 0.236 \\
\hline Fecal nitrogen $(\mathrm{g} / \mathrm{d})$ & $3.87^{\circ}$ & $4.57^{b}$ & $5.79^{a}$ & 5.79 & 3.70 & 4.74 & 5.65 & 6.96 & 3.00 & 3.48 & 4.62 & 0.069 & $<0.01$ & $<0.01$ & 0.218 \\
\hline Urine nitrogen $(\mathrm{g} / \mathrm{d})$ & $4.58^{b}$ & $4.65^{b}$ & $4.92^{\mathrm{a}}$ & 5.66 & 3.77 & $5.47^{\mathrm{b}}$ & $5.49^{b}$ & $6.02^{\mathrm{a}}$ & $3.70^{\mathrm{c}}$ & $3.80^{\mathrm{c}}$ & $3.82^{c}$ & 0.04 & $<0.01$ & $<0.01$ & 0.037 \\
\hline Nitrogen loss (g/d) & $8.46^{\mathrm{c}}$ & $9.21^{b}$ & $10.71^{\mathrm{a}}$ & 11.45 & 7.48 & 10.21 & 11.14 & 12.98 & 6.70 & 7.29 & 8.44 & 0.082 & $<0.01$ & $<0.01$ & 0.054 \\
\hline Nitrogen retention $(\mathrm{g} / \mathrm{d})$ & $17.30^{a}$ & $17.32^{\mathrm{a}}$ & $16.67^{b}$ & 17.79 & 16.40 & 18.03 & 17.97 & 17.36 & 16.57 & 16.67 & 15.98 & 0.091 & 0.014 & $<0.01$ & 0.934 \\
\hline Nitrogen digestibility (\%) & $85.15^{\mathrm{a}}$ & $83.04^{b}$ & $79.06^{c}$ & 80.29 & 84.55 & 83.21 & 80.60 & 77.06 & 87.09 & 85.48 & 81.07 & 0.198 & $<0.01$ & $<0.01$ & 0.546 \\
\hline Nitrogen retention, \% intake (\%) & $67.51^{\mathrm{a}}$ & $65.66^{\mathrm{b}}$ & $61.33^{c}$ & 60.93 & 68.74 & 63.85 & 61.72 & 57.22 & 71.18 & 69.6 & 65.43 & 0.239 & $<0.01$ & $<0.01$ & 0.749 \\
\hline Nitrogen biological value (\%) & $79.22^{a}$ & $79.00^{\mathrm{a}}$ & $77.49^{b}$ & 75.85 & 81.29 & 76.73 & 76.59 & 74.25 & 81.72 & 81.42 & 80.72 & 0.21 & $<0.01$ & $<0.01$ & 0.238 \\
\hline
\end{tabular}

NCAS, diet with normal protein content, based on casein; NBlend, diet with normal protein content, based on casein and corn gluten meal; NCGM, diet with normal protein content, based on corn gluten meal; LCAS, diet with low protein content, based on casein; LBlend, diet with a low protein content, based on casein and corn gluten meal; LCGM, diet with low protein content, based on corn gluten meal; SEM, standard errors of the mean.

${ }^{a-c}$ Within the same row, different superscript letters represent significant differences with respect to protein content, source, or both $(p<0.05)$. 
Table 5. Plasma insulin and urea nitrogen concentrations of piglets fed diets with differing protein content and source $(n=4)$

\begin{tabular}{|c|c|c|c|c|c|c|c|c|c|c|c|c|c|c|c|}
\hline \multirow{2}{*}{ Parameter } & \multicolumn{3}{|c|}{ Protein source } & \multicolumn{2}{|c|}{ Protein content } & \multicolumn{6}{|c|}{ Diet } & \multirow{2}{*}{ SEM } & \multicolumn{3}{|c|}{$\mathrm{p}$-value } \\
\hline & CAS & Blend & CGM & Normal & Low & NCAS & NBlend & NCGM & LCAS & LBlend & LCGM & & Source & Content & $S \times C$ \\
\hline Insulin (mmol/L) & 42.30 & 43.64 & 40.91 & 43.56 & 41.00 & 44.33 & 45.52 & 40.82 & 40.26 & 41.75 & 41.00 & 1.156 & 0.636 & 0.283 & 0.709 \\
\hline Plasma urea nitrogen (mIU/L) & $4.08^{\mathrm{b}}$ & $4.16^{\mathrm{b}}$ & $4.81^{\mathrm{a}}$ & 4.67 & 4.02 & 4.43 & 4.44 & 5.15 & 3.72 & 3.87 & 4.46 & 0.120 & 0.045 & 0.014 & 0.965 \\
\hline
\end{tabular}

NCAS, diet with normal protein content, based on casein; NBlend, diet with normal protein content, based on casein and corn gluten meal; NCGM, diet with normal protein content, based on corn gluten meal; LCAS, diet with low protein content, based on casein; LBlend, diet with a low protein content, based on casein and corn gluten meal; LCGM, diet with low protein content, based on corn gluten meal; SEM, standard errors of the mean.

$a, b$ Within the same row, different superscript letters represent significant differences with respect to protein content, source, or both $(p<0.05)$.

\section{Expression of mediators of muscle synthesis and degradation}

As shown in Figure 5, the CAS-containing diet and the mixed diet had lower expression of MuRF1 and MAFbx compared with the CGM-containing diet $(\mathrm{p}<0.05)$. The $\mathrm{p}-4 \mathrm{E}-\mathrm{BP} 1$ and p-S6K1 levels in the normal-protein diet groups were higher than in the low-protein diet groups $(\mathrm{p}<0.05)$.

\section{DISCUSSION}

In the present study, we have shown that a $2.65 \%$ unit (SID) reduction in CP content significantly reduces the growth performance of piglets, in contrast to the results of numerous previous studies [3-5], on the basis of which the authors concluded that reductions of $<4 \%$ unit $\mathrm{CP}$ did not affect growth performance. This difference may be explained by differences in the standards used. The "normal" protein content used in the present study was lower than NRC (1998) [15] requirement and the studies conducted, and in addition, the lowprotein diet $\mathrm{CP}$ content was $>5 \%$ unit lower than that of the "normal" diet. By contrast, Che et al [16] reported that the growth performance of piglets was decreased when the dietary protein content was reduced by $4 \%$ unit versus the NRC (2012) standard [7].

Even if sufficient levels of EAA are added, a low dietary protein concentration will still have adverse effects on piglets, which may be caused by deficiency of some conditionally essential amino acids (CEAA). Conditionally essential AA are defined as being able to be synthesized endogenously, but the efficiency of their synthesis is insufficient to keep pace with their utilization under particular circumstances, such as weaning, injury, and stress [17]. For piglets, the CEAA include Gln, Glu, Gly, and Pro, which play important roles in growth, development, and reproduction, and have been referred to as functional AA [18]. The phosphorylation of S6K1 and 4E-BP1, which are downstream intermediates in the mTOR signaling pathway, was higher in the muscle of pigs in the normal-protein diet groups than in pigs in the low-protein diet groups in the present study, which may be explained by deficiencies in NEAA. The mTOR signaling pathway is a key pathway in the regulation of protein synthesis, including in the regulation of expression of initiation and elongation factors, as well as of ribosome biogenesis itself, which can be activated by AA and growth factors, and inhibited by nutrient or energy deprivation [19]. Rezaei et al [20] showed that supplementation of a low-protein diet with Gln and Glu maintains the activation of translation initiation factors and optimal protein synthesis in young pigs. In addition, Hsu et al [21] showed that the addition of Gln to the diet improves villous morphology and the xylose absorption capacity of the small intestine, and thereby growth performance. Finally, Kirchgessner et al [22] showed that the addition of Pro increases the ADG and G:F and reduces the PUN of piglets in a dose-dependent manner.

Corn gluten meal is a byproduct of the maize industry that is rich in Leu [23] and can serve as an unconventional protein source for piglets $[24,25]$. Casein is a high-quality animal protein that is abundant in EAA, has a balanced AA composition, and has a true digestibility of almost $100 \%$ in pigs. Casein and CGM have different concentrations of AA and SID of AA, and therefore, to equalize the quantities of TFAA and individual FAA released from each in the GIT of the pigs, we used the SID to formulate the diets and supplemented them with the corresponding FAA.

The release of FAA in the intestine is faster than that of protein-derived AA $[16,26]$. The disparity in the CGM groups was often higher than in the CAS and Blend groups because the release of AA was slower from the CGM diets. Different protein sources have differing compositions and structures, which affects their solubility and digestibility $[11,27]$. Zein is present at a high concentration in CGM, and this contains numerous hydrophobic AA and S-S and $\mathrm{O}-\mathrm{H}$ bonds that promote stable $\alpha$-helical structure formation [12], both of which render zein poorly soluble in water. In addition, the poor digestibility of plant-based proteins in piglets may be due to incomplete development of digestive enzymes [24]. Abdallah et al [13] compared the in vitro digestion of SBM, fish meal, CGM, and fermented SBM over $28 \mathrm{~h}$, and found that the FAA release from CGM diet was significantly lower than the release from the other diets at between 8 and $20 \mathrm{~h}$, and did not reach the same level until 24 to $28 \mathrm{~h}$, which indicates that AA are released more slowly from CGM. In the present study, we found that the peak AA release from CAS during trypsin digestion was within 0 to $4 \mathrm{~h}$, whereas the 


\section{NCAS NBlend NCGM LCAS LBlend LCGM}
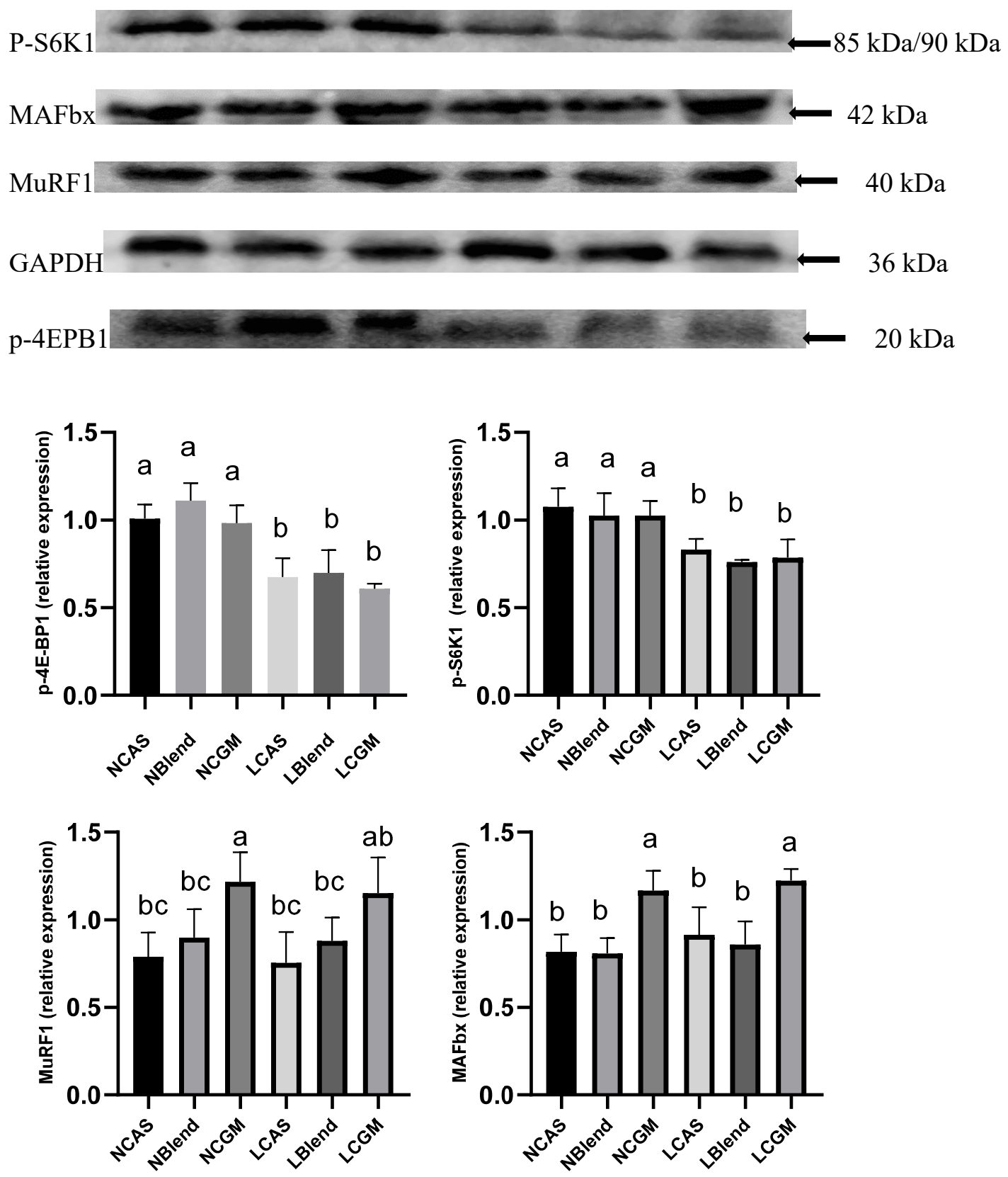

Figure 5. Protein expression of key mediators of muscle synthesis and degradation in each group. NCAS, diet with normal protein content, based on casein; NBlend, diet with normal protein content, based on casein and corn gluten meal; NCGM, diet with normal protein content, based on corn gluten meal; LCAS, diet with low protein content, based on casein; LBlend, diet with a low protein content, based on casein and corn gluten meal; LCGM, diet with low protein content, based on corn gluten meal; p-4E-BP1, phosphorylated elF 4E binding protein-1; p-S6K1, phosphorylated ribosomal protein S6 kinase; MuRF1, muscle ring finger 1; MAFbx, muscle atrophy F-box. ${ }^{\mathrm{a}-\mathrm{c}}$ In each panel, different superscript letters represent significant differences $(p<0.05)$.

peak AA release from CGM was at 16 to $20 \mathrm{~h}$. The slow release of AA from CGM proteins, in contrast to the fast release of the added FAA, exaggerates the degree of AA imbalance associated with this diet. Conversely, CAS is rapidly hydrolyzed in piglet intestine [6], such that the imbalance was lower in the CAS groups.
In the present study, the CGM diets were associated with lower growth performance, nitrogen digestibility, and nitrogen retention, \% intake than the CAS and Blend groups, which may have been related to the lower hydrolysis or dissolution rates of CGM. A similar conclusion was reached by Asche et al [24]. Even though the CGM, CAS, and Blend diets shared 
the similar SID AA, the differing digestion dynamics of the protein sources may have a significant effect on $\mathrm{N}$ availability. When AA are released asynchronously from a diet, particular AA may appear in large amounts in the small AA pool of the piglets, whereas others that are necessary for protein synthesis are present in insufficient quantities, resulting in the deamination of the excess. The higher concentrations of PUN and urinary $\mathrm{N}$ that were identified in the CGM groups in the present study are consistent with this explanation.

There were no differences in the phosphorylation of S6K1 or $4 \mathrm{E}-\mathrm{BP} 1$ between the piglets fed the CAS, Blend, and CGM diets in the present study, but the expression of the E3 ligases MuRF1 and MAFBx, which form part of the UPP, was higher in the CGM groups than in the CAS or Blend groups. Skeletal muscle MAFbx and MuRF1 are generally considered to be the principal mediators of protein degradation, which is closely related to muscle atrophy [28]. We speculate that the rate of protein degradation in the CGM groups was higher to maintain muscle synthesis in skeletal muscle because of the deficiency of some AA. Luo et al [29] showed that growing rats fed zein had higher mRNA muscle expression of MuRF1 and MAFBx than those that were fed CAS or soy protein isolate. Moreover, the feeding of low-protein diets reduces protein intake, but more FAA are often added to such diets to meet the EAA requirements of the piglets, which may increase the imbalances in the AA supplied, resulting in poorer growth performance [26]. However, the imbalance in AA supply was similar in the low- and normal-protein versions of the CAS, Blend, and CGM diets in the present study, which may be because the TAA supply was also altered by the larger amounts of CAA that were added to the low-protein diets.

The fecal $\mathrm{N}$ content was higher and $\mathrm{N}$ utilization was lower in the CGM groups than in the CAS groups, which might be because the intake of $\mathrm{N}$ in the CGM groups was higher. To equalize the SID CP, CGM-based diets often have higher airdried basic CP than CAS-based diets. Reducing N intake has been widely shown to reduce $\mathrm{N}$ loss and PUN, and increase $\mathrm{N}$ utilization in piglets $[30,31]$. However, these effects might be because of the suboptimal digestion of CGM. Casein is absorbed faster in the GIT and is associated with slower GIT emptying [25], which allows its component AA to be fully absorbed and utilized. However, AA release from CGM is highest in the distal small intestine; therefore, the AA cannot be efficiently absorbed [24]. Nevertheless, faster AA release is not necessarily better. Rivest et al [27] simulated porcine small intestinal digestion and showed that the absorptive capacity of the small intestine limits its absorption of AA. Therefore, excess provision of AA may lead to the upper absorption limit of the intestine being exceeded, resulting in AA loss.

Studies of the effects of exercise on muscle synthesis in humans and the relationship with the rate of digestion of ingested proteins have demonstrated that the consumption of rapidly digested proteins, such as whey, causes a rapid, temporary rise in plasma AA concentrations, but this also results in the oxidation and loss of excess $\mathrm{AA}$, whereas the consumption of slowly digested proteins, such as CAS and soybean protein, is associated with modest but more sustained increases in plasma AA concentrations [10,32]. Exercise promotes the utilization of AA by skeletal muscle, and earlyweaning piglets are a good model of the utilization of AA because of the fast-growing nature of piglet muscle [33]. Reidy et al [10] suggested that a mixture of proteins could combine the advantages of rapidly digested proteins with those of more slowly digested proteins, which would sustain the phosphorylation of S6K1 and the peak fractional synthetic rate for a longer period of time after the appearance of hyperammonemia. However, there were no significant differences in growth performance, $\mathrm{N}$ utilization, or protein expression of mTOR and components of the UPP between the CAS and Blend groups in the present study, which may be attributed to their similar AA content. Although CAS was found to release AA more slowly than whey in the previous study [10,32], CAS had higher digestibility than CGM in the present study. In addition, the previous studies described above were conducted in humans who ingested single meals of each protein, and there were few long-term feeding trials, which would be more similar to the present study.

The induction of translation by insulin and AA in the postprandial skeletal muscle of piglets is a key factor in the rapid neonatal growth of muscle [34]. In the present study, there were no significant differences in plasma insulin between the groups. Therefore, the differences in growth performance and nitrogen deposition may be caused by the differing availability of AA [33]. Atinmo et al [35] showed that limiting the protein content of a diet reduces the insulin concentrations of piglets. In addition, Deng et al [2] fed piglets a low-protein diet supplemented with EAA, and showed that the insulin concentration did not significantly differ from that of the control group, which implies that insulin secretion may be affected by the EAA supply.

\section{CONCLUSION}

In summary, there were no differences in nitrogen deposition or growth performance in piglets between the CAS and Blend groups. By contrast, piglets fed the CGM-based diets showed lower nitrogen retention, and \% intake, probably because of a relative imbalance in AA release. We conclude that moderate and steady release of $\mathrm{AA}$, whether from a protein-limited diet or not, is beneficial for the maximization of nitrogen deposition. However, further work is needed to confirm this finding and to identify the most critical growth 
periods.

\section{CONFLICT OF INTEREST}

We certify that there is no conflict of interest with any financial organization regarding the material discussed in the manuscript.

\section{FUNDING}

This work was supported by the National Natural Science Foundation of China (grant nos. 31572439 and 31572415), the Natural Science Foundation of Jilin Province of China (grant no. 20160101348JC), and the Key Technology Research and Development Program of Jilin Province of China (grant no. $20180201018 \mathrm{NY}$ ).

\section{REFERENCES}

1. Wang Y, Zhou J, Wang G, Cai S, Zeng X, Qiao S. Advances in low-protein diets for swine. J Anim Sci Biotechnol 2018; 9:60. https://doi.org/10.1186/s40104-018-0276-7

2. Deng D, Yao K, Chu W. Impaired translation initiation activation and reduced protein synthesis in weaned piglets fed a low-protein diet. J Nutr Biochem 2009;20:544-52. https://doi.org/10.1016/j.jnutbio.2008.05.014

3. Nyachoti CM, Omogbenigun FO, Rademacher M, Blank G. Performance responses and indicators of gastrointestinal health in early-weaned pigs fed low-protein amino acidsupplemented diets. J Anim Sci 2006;84:125-34. https://doi. org/10.2527/2006.841125x

4. Heo JM, Kim JC, Hansen CF, Mullan BP, Hampson DJ, Pluske JR. Effects of feeding low protein diets to piglets on plasma urea nitrogen, faecal ammonia nitrogen, the incidence of diarrhoea and performance after weaning. Arch Anim Nutr 2008;62:343-58. https://doi.org/10.1080/17450390802327811

5. Yue LY, Qiao SY. Effects of low-protein diets supplemented with crystalline amino acids on performance and intestinal development in piglets over the first 2 weeks after weaning. Livest Sci 2008;115:144-52. https://doi.org/10.1016/j.livsci. 2007.06.018

6. Zhong RZ, Xia JQ, Sun H, Qin GX. Effects of different sources of protein on the growth performance, blood chemistry and polypeptide profiles in the gastrointestinal tract digesta of newly weaned piglets. J Anim Physiol Anim Nutr 2017;101: e312-22. https://doi.org/10.1111/jpn.12607

7. NRC. Committee on nutrient requirements of swine. Nutrient requirements of swine. 11th rev. ed. Washington, DC, USA: National Academy Press; 2012.

8. Stoll B, Henry J, Reeds PJ, Yu H, Jahoor F, Burrin DG. Catabolism dominates the first-pass intestinal metabolism of dietary essential amino acids in milk protein-fed piglets. J
Nutr 1998;128:606-14. https://doi.org/10.1093/jn/128.3.606

9. Boirie Y, Dangin M, Gachon P, et al. Slow and fast dietary proteins differently modulate postprandial protein accretion. Proc Natl Acad Sci USA 1997;94:14930-5. https://doi.org/10. 1073/pnas.94.26.14930

10. Reidy PT, Walker DK, Dickinson JM, et al. Protein blend ingestion following resistance exercise promotes human muscle protein synthesis. J Nutr 2013;143:410-6. https://doi. org/10.3945/jn.112.168021

11. Boisen S, Ferna'ndez JA. Prediction of the apparent ileal digestibility of protein and amino acids in feedstuffs and feed mixtures for pigs by in vitro analyses. Anim Feed Sci Technol 1995;51:29-43. https://doi.org/10.1016/0377-8401 (94)00686-4

12. Bai M, Qin G, Sun Z, Long G. Relationship between molecular structure characteristics of feed proteins and protein in vitro digestibility and solubility. Asian-Australas J Anim Sci 2016; 29:1159-65. https://doi.org/10.5713/ajas.15.0701

13. Abdallah A, Wang J, Elemba E, et al. Amino acid release patterns of growing pig diets formulated with different dietary protein sources. J Appl Anim Res 2019;47:417-22. https://doi.org/10.1080/09712119.2019.1651318

14. Williams S. Official methods of analysis. Association of Official Analytical Chemists. Arlington, VA, USA: AOAC; 1984.

15. NRC. Committee on nutrient requirements of swine. Nutrient requirements of swine. 10th rev. ed. Washington, DC, USA: National Academy Press; 1998.

16. Che LQ, Peng X, Hu L, et al. The addition of protein-bound amino acids in low-protein diets improves the metabolic and immunological characteristics in fifteen-to thirty-fivekg pigs. J Anim Sci 2017;95:1277-87. https://doi.org/10.2527/ jas.2016.0990

17. Wu G. Functional amino acids in nutrition and health. Amino Acids 2013;45:407-11. https://doi.org/10.1007/s00726-0131500-6

18. Wu G. Amino acids: metabolism, functions, and nutrition. Amino Acids 2009;37:1-17. https://doi.org/10.1007/s00726009-0269-0

19. Wang X, Proud CG. The mTOR pathway in the control of protein synthesis. Physiology 2006;21:362-9. https://doi.org/ 10.1152/physiol.00024.2006

20. Rezaei R, Wang W, Wu Z, et al. Biochemical and physiological bases for utilization of dietary amino acids by young pigs. J Anim Sci Biotechnol 2013;4:7. https://doi.org/10.1186/20491891-4-7

21. Hsu CB, Huang HJ, Wang CH, Yen HT, Yu B. The effect of glutamine supplement on small intestinal morphology and xylose absorptive ability of weaned piglets. Afr J Biotechnol 2010;9:7003-8.

22. Kirchgessner VM, Fickler J, Roth FX. Effect of dietary proline supply on N-balance of piglets, 3: the importance of nonessential amino acids for protein retention. J Anim Physiol 
Anim Nutr 1995;73:57-65.

23. Liang G, Li D, Wang F, Dai J, Yang W. Evaluation of apparent ileal digestibility of amino acids in Chinese corn by-products for growing-finishing pigs. Arch Anim Nutr 2003;57:11725. https://doi.org/10.1080/0003942031000107316

24. Asche, GL, Lewis AJ, Peo Jr ER. Protein digestion in weanling pigs: effect of dietary protein source. J Nutr 1989;119:10939. https://doi.org/10.1093/jn/119.8.1093

25. Mahan DC. Evaluating two sources of dried whey and the effects of replacing the corn and dried whey component with corn gluten meal and lactose in the diets of weanling swine. J Anim Sci 1993;71:2860-6. https://doi.org/10.2527/ 1993.71112860x

26. Yen JT, Kerr BJ, Easter RA, Parkhurst AM. Difference in rates of net portal absorption between crystalline and proteinbound lysine and threonine in growing pigs fed once daily. J Anim Sci 2004;82:1079-90. https://doi.org/10.2527/2004. 8241079x

27. Rivest J, Bernier JF, Pomar C. A dynamic model of protein digestion in the small intestine of pigs. J Anim Sci 2000;78: 328-40. https://doi.org/10.2527/2000.782328x

28. Tesseraud S, Bouvarel I, Collin A, et al. Daily variations in dietary lysine content alter the expression of genes related to proteolysis in chicken pectoralis major muscle. J Nutr 2009; 139:38-43. https://doi.org/10.3945/jn.108.095752

29. Luo J, Chen D, Yu B. Effects of different dietary protein sources on expression of genes related to protein metabolism in growing rats. Br J Nutr 2010;104:1421-8. https://doi.org/10.
1017/S000711451000231X

30. Kerr BJ, McKeith FK, Easter RA. Effect on performance and carcass characteristics of nursery to finisher pigs fed reduced crude protein, amino acid-supplemented diets. J Anim Sci 1995;73:433-40. https://doi.org/10.2527/1995.732433x

31. Peng X, Hu L, Liu Y, et al. Effects of low-protein diets supplemented with indispensable amino acids on growth performance, intestinal morphology and immunological parameters in 13 to $35 \mathrm{~kg}$ pigs. Animal 2016;10:1812-20. https://doi.org/ 10.1017/S1751731116000999

32. Burke LM, Winter JA, Cameron-Smith D, et al. Effect of intake of different dietary protein sources on plasma amino acid profiles at rest and after exercise. Int J Sport Nutr Exerc Metab 2012;22:452-62. https://doi.org/10.1123/ijsnem.22.6. 452

33. Davis TA, Fiorotto ML, Beckett PR, et al. Differential effects of insulin on peripheral and visceral tissue protein synthesis in neonatal pigs. Am J Physiol Endocrinol Metab 2001;280: E770-9. https://doi.org/10.1152/ajpendo.2001.280.5.E770

34. O'Connor PMJ, Kimball SR, Suryawan A, et al. Regulation of translation initiation by insulin and amino acids in skeletal muscle of neonatal pigs. Am J Physiol Endocrinol Metab 2003;285:E40-53. https://doi.org/10.1152/ajpendo.00563. 2002

35. Atinmo T, Baldijåo C, Pond WG, Barnes RH. Plasma insulin levels in weaned pigs fed protein or energy restricted diets. J Nutr 1976;106:1654-8. https://doi.org/10.1093/jn/106.11. 1654 